\title{
Evaluating How Potential Pool of Partners Can Join Together in Different Types of Long Term Collaborative Networked Organizations
}

\author{
Andrea Cardoni ${ }^{1}$, Stefano Saetta ${ }^{2}$, and Lorenzo Tiacci ${ }^{2}$ \\ ${ }^{1}$ Università degli Studi di Perugia - Dipartimento di Discipline Giuridiche e Aziendali \\ Via Pascoli, 20 - 06123 Perugia, Italy \\ ${ }^{2}$ Università degli Studi di Perugia - Dipartimento di Ingegneria Industriale \\ Via Duranti, 67 - 06125 Perugia, Italy \\ \{acardoni, stefano.saetta, lorenzo.tiacci\}@unipg.it
}

\begin{abstract}
The considerable benefits brought up by strategic alliances and diverse types of long term Collaborative Networked Organizations (CNOs) are nowadays widely recognized. There is an increasing demand in the industrial world for concretely implement new forms of collaborations. For example, demand often comes from pre-existent form of clusters or local productive arrangements, that want to evolve to more efficient forms of collaboration, or from small and medium enterprises that are facing a crisis, and look at collaboration with other enterprises as almost the last chance to survive. In general, variety of motivations in collaborating implies variety of missions of potential collaborations, that in turn requires the choice of an appropriate form of Collaborative Network aligned to the mission statement. This paper addresses the problem to define a methodology for analyzing potential pool of partners and for identifing the mission, the form, the governance structure and the value drivers of long term strategic alliance that would bring highest benefits to the partners. Three different forms of CNOs are considered: the Virtual organizations Breeding Environment (VBE), the Virtual Development Office (VDO) and the T-Holding.
\end{abstract}

Keywords: Network Mission, CNs creation, VBE, VDO, T-Holding.

\section{Introduction}

In recent years the economy have developed a deep changes involving the increasing importance of the knowledge in the economic and social development. This has significantly altered the paradigm of industrial development, based on the traditional division between labor and capital factors, identifying a new category of assets attributable to cognitive and relationship attitudes and skills.

In this context the traditional market and business structures that had supported the industrial development for the last two centuries have shown some limits to control efficiently the new form of coordination and the new challenges emerging from the so-called "knowledge economy"[1][2][3]. The creation of the hybrid form of coordination [4] able to combine all the benefits deriving form the competitive 
transactions with the stability and the performance control of the organization has been indicated as the right strategy to adapt the business structure to the main features of the knowledge economy (positive externalities, increasing productivity and the market failures) introducing the background framework for what is possible to define the "network vision".

The economic literature has followed this evolutionary process by providing ample evidence of the importance of knowledge and intangible assets and the same policies developed by the Community authorities have set a strategic goal of making Europe "the knowledge-based economy more competitive and dynamic world" (Lisbon strategy), highlighting the need of a hybrid form of organization between market and hierarchies.

From different perspectives also the industrial and management literature increasingly highlights the need to promote the networked organization developing a broad interdisciplinary approach to deepen the strategic and operational issues [5][6][7][8]. Developments in Collaborative Networks have benefited from contributions of multiple disciplines, namely computer science, computer engineering, communications and networking, management, economy, social sciences, law and ethics, etc. [9]. Referring to particular economic context characterized by the presence of SMEs, many important contributes also found that the network strategy has particular importance for small and medium-sized businesses [10][11][12] and entrepreneurial business [13], allowing them to activate the processes of growth and globalization that are necessary for the acquisition and the preservation of competitive advantage in the knowledge economy.

Although from existent literature the network vision appears as a consolidated way to face the new market challenges, and different cooperative networks structures have been proposed, it has been assumed that, for each type of theses, a specific collaborative mission has already been defined. However it can be highlighted the importance to investigate the conceptual steps that lead to the choice of the most appropriate strategic mission (and consequently the associated type of collaborative network), based on the characteristics of a potential pool of partners (see Fig. 1).

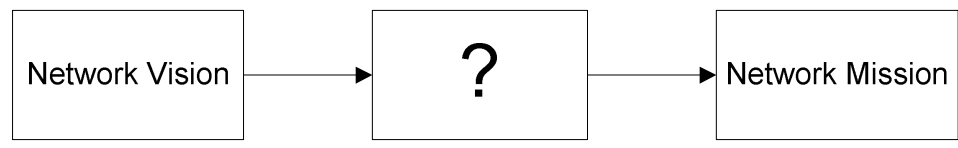

Fig. 1. The missing conceptual steps that link a network vision to a network mission definition

Putting these theoretical references as fundamental assumptions, the present paper is intended to focus attention on the process that guides a group of companies with a "network vision" to define the strategic mission of a networked organization project. The work is inspired by a real case: a study commissioned by the ICE (the Italian Institute for Foreign Trade) and by a local industrial association (Confartigianato Terni) to the University of Perugia, in order to investigate how the companies belonging to an industrial cluster of the metal-mechanic industry in Italy could be aggregated in an innovative way. The study is still in progress, and the present work just intends to illustrate the conceptual steps that are needed to approach the problem in order to define a framework that will be validated through the implementation of the case study. 
The study follows a deductive interdisciplinary approach based on the rich literature about networked organization and presents the main conceptual steps to move a group of companies from the network vision to the definition of a strategic network mission. Firstly our analysis will describe three types of collaborative networks and combinations, that are characterized by different degree of business and process integration, namely: VBE, VDO e T-HOLDING. Secondly the strategic goals on which aggregation and collaboration forms can be based are identified and classified; the three above mentioned forms are then assessed on the basis of their capability to be aligned with the different strategic goals. Finally the analytical tools that allow to evaluate which strategic goals are attainable by a potential pool of companies are identified. On the basis of this results, the collaborative strategic network mission can be defined, and in turn the most appropriate collaborative form can be chosen.

Note that the procedure presented here in has been developed considering three possible collaborative network forms, taken as representative of long term collaboration forms with different integration degree. However, the methodology is generalizable and can be extended to include other forms of collaborative networks.

\section{Three Possible Ways of Collaboration/Aggregation}

VBE (Virtual Organizations Breeding Environment). VBE is a strategic association/alliance of organizations and the related supporting institutions, adhering to a base long term cooperation agreement and adoption of common operating principles and infrastructures, with the main goal of increasing their preparedness towards collaboration in potential Virtual Organizations [14]. That is, when an opportunity of business is identified by one of the members (what it acts as broker), a subset of the organizations of the VBE can be selected to form a VO / VE (Virtual Organization / Virtual Enterprise). A VO "is an association of (legally) independent organizations (VO partners) that came together and share resource and skills to achieve common goals, such as acquiring and responding to a market/society opportunity" [15].

The VBE maintains and manages well classified repositories/catalogs of information regarding the profile, competence, resource, production, service, ect. about its member organizations. Different member of the VBE, depending on their role/right, can have access to and use this information, e.g. for a broker to react on new business opportunities, for a VO coordinator to replace a failing partner in the VO, etc. In addition, the VBE results to be an innovative model as is offers an infrastructure base common ITC to facilitate the formation and the collaboration of the Virtual Organizations [16]. The VBE is an ampler concept of industry cluster, industry district, business echo system, virtual laboratories and crises management that operates only to regional level and they is essentially focused on a product / service. It is a more recent term that was coined to cover these cases and clearly extends their scope to both regional and global coverage, single and multi-specialty sector, and for-profit/ non profit organizations [17].

Romero and Molina [18] provide a framework that describes a set of process models that depict what happens during each VBE and VO management processes, to provide rationale of activities that should be carried out by a set of VBE actors to achieve the expected business process results. 
VDO (Virtual Development Office). VDO organizational model has been developed inside of the MIGEN research project [18]. The model provides a central entity, namely the Virtual Development Office (VDO), which has tasks of creation, coordination and management of the network of enterprises, supplying some interface with the market and guaranteeing the consolidation of relations of mutual confidence between the actors of the community in an optical of strategic alliance of long period. The VDO acts as unique interlocutor toward the ecosystem of Business, it favours both the wish of cooperation and to the collaboration every time that introduces a Collaboration Opportunity.

The former definition is [20]: "VDO is a network entity with the aim to identify competitive positioning of the network enterprise and to promote, within the network, business missions". This definition clarifies what is a VDO, the entity introduced to manage the Collaborative Network, but does not clearly explain the role of the Network if compared to the VBE. In this sense it can be possible to formulate a new definition, based on the VBE one, that clarifies the VDO network model as "A strategic association/alliance of organizations and the related supporting institutions, adhering to a base long term cooperation agreement and adoption of common operating principles and infrastructures, with the main goal to create innovative BOs. This goals is accomplished by introducing a new for-profit company, the VDO, operating as a permanent network management/coordination entity. In pursuing these business opportunities the VDO realizes VOs and VEEs of network members and/or external partners". From this definition it is noteworthy that VDO is similar to VBE but it focused in particular on innovative businesses. VDO promotes research, marketing and innovation and is continuously looking for Business Opportunities. In this sense it acts as a permanent broker. VDO members focus on their core business keeping traditional activities and independence, but they can increase their competitiveness thanks to the activities of the VDO, which is always searching for innovative BOs. With VEE, VDO addresses explicitly the fact that it can include external partners.

If we make a comparison between VDO and VBE it can be observed a higher degree of coordination because of the VDO entity presence. VDO is also proactive because it promotes research, innovation, marketing within the network, due to its nature of for profit company and the connected need to reach a profitable dynamic. VDO does not wait for a $\mathrm{BO}$ from the single members but it is itself the proactive broker. Also, VDO always plays the role of VO/VEE planner and coordinator.

T-Holding. T-Holding is an aggregation model that represents the result of a collaboration project between the University of Perugia and "Piccola Industria", which is the branch dedicated to SMEs of the principal Italian industrial association, "Confindustria". Founded in 1910 Confindustria is the leading organization representing the manufacturing, construction, energy, transportation, ICT, tourism and services industries in Italy. The model has been officially presented during the XI Forum of "Piccola Industria" in Mantova (Italy) (23-24 October 2009), and attracted the national press and media attention thanks to the high potential impact of its application on the Italian industrial structure, impact that has been simulated through a scenario analysis.

The letter "T" stands for 'protection' (from the Italian word "Tutela") of small and medium enterprises that risk to lose their capacity of maintaining competitiveness and profitability in the new economic scenario. The basic idea is to avoid the collapse and the disappearance of these companies in crisis thanks to a strong push to the 
aggregation: for example, a number of companies in crisis could considerate the possibility of aggregation through the formation of a new company (namely the T-Holding). This new company should be in a position able to guarantee the industrial continuity and consequently to safeguard the industrial, entrepreneurial, financial and occupational patrimonies otherwise destined to a destruction process. The T-Holding should be born from an aggregation that involves a consistent number of firms belonging to compatible market sectors or supply chains.

The model was originally created in order to be applied to SMEs that are facing a deep financial and economic crisis. However, the model can be utilised also to aggregate companies that not necessarily are facing a crisis, and can be viewed as the model with the stronger degree of integration with respect to the others two models, the VBE and the VDO (Figure 1). The mechanism is the following: the entrepreneur transfers the ownership of its own firm (both tangible and intangible assets) to the THolding and becomes shareholder of this new company, acquiring a number of shares (or stocks) on the base of the assets value that are brought to the newco. The entrepreneur can also assume an operative role (partner-entrepreneur), for example being responsible for the production function of the plant. In other cases the entrepreneur could just participate as a financial partner, without executive responsibilities. The strategic and operative Governance is assigned to an "Industrial Manager", that is responsible for the industrial strategy and for the general management, while a "Financial Manager" is responsible for the financial and economical planning. This aggregation is based on the strategic principles of acquisition of the competitive advantage through the careful analysis of needs, and the development of innovative products obtained implementing high value added processes. These objectives become feasible through the sharing of:

- existing markets, controlled by the companies participating in the aggregation;

- plants and technology, with the ability to optimize their use, by reducing, if necessary, the production sites;

- competences and business skills, both those ones related to production processes and those ones related to the resources that are responsible of the managerial leadership of the new company;

- administrative and financial structures, to allow the reduction of overhead costs, to limit the financial debt and to renegotiate the account payable to suppliers and banks;

- commercial organizations, to rationalize market penetration policies;

- supply units, to allow the reduction of raw materials and services purchasing costs.

\section{Strategic Goals Identification}

The first step that links the network vision to the network mission definition is the strategic goals identification (see Fig. 2). The study and the experimentation on corporate networks have identified a number of strategic goals on which you can build an aggregation. The main reasons why firms aim to start an alliance of long period, of different sizes and with different integration degrees (ranging from a "soft" to a "strong" integration) should be referred to a combination of 'Primary' and 'Secondary' strategic goals. 


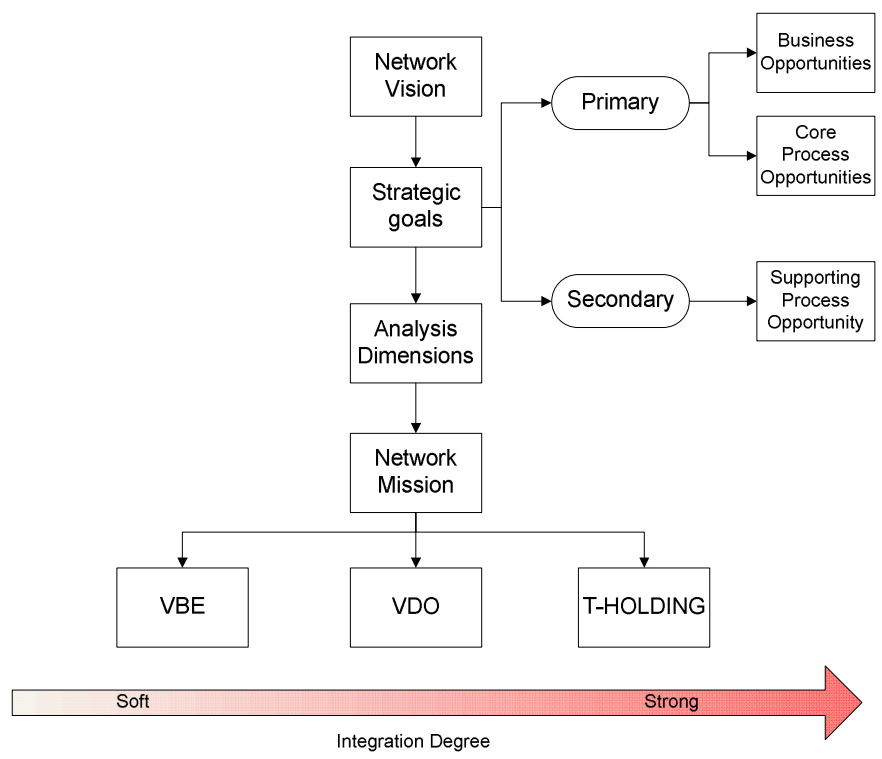

Fig. 2. The steps that link the network vision to the network mission definition, and the choice of the appropriate aggregation form.

The strategic goals of Primary type represents the ability of the network to permanently increase the value added related to its business core competencies. To achieve these goals it is necessary that the alliance is able to create new Business Opportunities (BOs) and Core Process Opportunities (CPOs):

- Business Opportunities: are related to new markets and new products development, able to increase the network turnover;

- Core Process Opportunities: are related to the increase of effectiveness and efficiency of the core operational activities, able to reduce the network costs.

In the strategic goals of Secondary type we can include all the other synergies that brings to new Supporting Process Opportunities, that are related to increase the efficiency and effectiveness of all the supporting activities, such as finance, control, quality, research, administration, education, etc., that are able to emphasize the benefits of Primary type.

Each kind of strategic goal (BOs, CPOs, SPOs) can be achieved in a stable or occasional manner, depending on the persistence and the intensity of the network effect. Table 1 shows that each one of the three aggregation form analysed is based on the three strategic goals that we have defined. However the identification of the different impact on each of the strategic goal can support the choice for the most appropriate network model and the related strategic mission.

If the opportunities tends to be occasional, due for example to high market instability or hard processes integration, it is undesirable to introduce a new for-profit company (the VDO). In this case the VBE seems to be the best model to maximize the cooperation benefits. On the contrary, when the companies are able to share in a persistent way the stable benefits of cooperation, the VDO and T-Holding models are more 
Table 1. New Business and Process Opportunities in each of the three types of aggregation considered.

\begin{tabular}{|c|c|c|c|c|}
\cline { 3 - 5 } \multicolumn{2}{c|}{} & VBE & VDO & T-Holding \\
\hline \multirow{3}{*}{ Business Opportunities } & Stable & + & +++ & ++ \\
\cline { 2 - 5 } & Occasional & ++ & + & + \\
\hline \multirow{2}{*}{$\begin{array}{c}\text { Core Process Opportuni- } \\
\text { ties }\end{array}$} & Stable & + & ++ & +++ \\
\cline { 2 - 5 } & Occasional & ++ & + & + \\
\hline $\begin{array}{c}\text { Supporting Process } \\
\text { Opportunities }\end{array}$ & Stable & +++ & + & +++ \\
\cline { 2 - 5 } & Occasional & +++ & ++ & + \\
\hline
\end{tabular}

valuable models, with a preference for the first model when the network shows the potential to strongly increase new Business Opportunities, and for the second one when the combination of the business structures allow to maximize processes synergies.

\section{Analysis Dimensions}

In this step we identify which are the analysis dimensions through which assess a potential pool of companies in order to evaluate the possibility that their aggregation brings to new Business Opportunities, Core Process Opportunities and Supporting Process Opportunities, that is, to fulfill the strategic goals that have been defined in the previous step. Firstly it is necessary to identify and assess the business model of each company included in the pool of potential partners using an appropriate framework of analysis. We propose to focus on two main perspectives represented by the strategic business in which the company operates and the processes implemented to plan and manage the operations. From the theoretical view the analysis of strategic business of the company could be obtained by using the Abell [22] definition of Segments of Business: "A business may be defined in three dimensions. Customer groups describe categories of customers, or who is being satisfied. Customer functions describe customer needs, or what is being satisfied. Technologies describe the way, or how customer needs are satisfied". Thus with the Abell analysis the business model is represented through the use of this three dimensions, and in particular:

- Served Customer Group concerns the customer segments that can be interested to the products or to the services of the enterprise;

- Served customer function is finalized to underline the needs that the enterprise intends to satisfy;

- Technologies utilized suggest the alternative ways in which the need can be satisfied.

In order to evaluate the process capabilities we suggest the Porter's [21] value chain approach, which is based on the identification and evaluation of 'primary' and 'supporting' activities. The first ones are directly involved in the logistics and operations flow, and are: 
- Inbound Logistics: includes receiving, storing, inventory control, transportation scheduling.

- Operations: includes machining, packaging, assembly, equipment maintenance, testing and all other value-creating activities that transform the inputs into the final product.

- Outbound Logistics: the activities required to get the finished product to the customers: warehousing, order fulfillment, transportation, distribution management.

- Marketing and Sales: The activities associated with getting buyers to purchase the product including channel selection, advertising, promotion, selling, pricing, retail management, etc.

- Service: the activities that maintain and enhance the product's value, including customer support, repair services, installation, training, spare parts management, upgrading, etc.

The second ones facilitate the primary activities, and are represented by:

- Procurement: procurement of raw materials, servicing, spare parts, buildings, machines, etc.

- Technology Development: includes technology development to support the value chain activities, such as Research and Development, Process automation, design, redesign.

- Human Resource Management: the activities associated with recruiting, development (education), retention and compensation of employees and managers.

- Firm Infrastructure: includes general management, planning management, legal, finance, accounting, public affairs, quality management. etc.

The results of the analysis conducted thorough the above mentioned models has to be integrated by the assessment of the critical resources hold by each company, following the resource based view [23]. According to this view, firms resources "include all assets, capabilities, organizational processes, firms attributes, information, knowledge, etc.; controlled by a firm that enable the firm to conceive of and implement strategies that improve its efficiency and effectiveness" [24].

Finally the evaluation process on a single firm basis should be completed with a financial statement analysis in order to measure the economic performance and appraise the financial position of the company.

Evaluating and consolidating all the information gathered in a network perspective will allow to define the types of occasional/stable Business/Process Opportunities that in turn allow to identify the most appropriate strategic mission for the collaborative network. Particularly the strategic business analysis will be implemented on a network basis to assess the capability of a pool of companies to generate new Business Opportunities and to understand how potential partner compete each other and complement each other.

On the other side, the identification of the business processes and the critical resources of the companies together with the performance measurement will allow to assess the capabilities to obtain new Process Opportunities and to understand how competent and competitive is each firm in terms of cost and delivery. It is noteworthy that our definition of Supporting Process Opportunities is based on a concept of supporting activities that matches with the Porter's definition of Firm Infrastructure 
supporting activity. As far as the other Porter's supporting activities are concerned, it is necessary a further investigation to asses if they could bring to Core Process Opportunities or just Supporting Process Opportunities, depending on the type of synergy that the network could allow. For example, the Procurement activity in a network organization may not be considered just as a supporting activity, due to its high potential of increase the economic value added (as in the case of an extended Collaborative Procurement agreement between companies).

\section{Conclusions}

In the paper, we presented a general framework to investigate the missing conceptual steps that link the network vision to the definition of a strategic network mission. The choice of the strategic goals for the collaborative network is a crucial analytical phase that determines the most appropriate form of alliance. In general, when analyzing a pool of company that wants to collaborate, strategic network goals are not defined 'a priori', but should be the result of an assessment of the possible opportunities deriving from the collaboration. Firstly we identified a different level of possible strategic goals, Primary and Secondary on the basis of the different impact on value added creation. Primary strategic goals can be achieved through the turnover increase generated by new products and market developments (new Business Opportunities), as well as through an operative cost decrease obtainable through the increase of the effectiveness of the core operational activities (Core Process Opportunities). Secondary strategic goals are obtained through the benefits deriving from the collaborative implementation of supporting activities.

The impact and the persistence (stable/occasional) of these opportunities influence the choice of the most appropriate collaborative network form. To asses the opportunities that can potentially arise from an aggregation of a pool of partner a general framework is identified. This framework will be further developed in more detail and tested on real case study, arising from a project commissioned to the University of Perugia, concerning a pool of companies belonging to an industrial cluster of the metal-mechanic industry in Italy.

\section{References}

1. Vitro, R.A. (ed.): The knowledge economy in development: perspectives for effective partnerships, Washington, D.C (2005)

2. Cowan, R., Foray, D.: The Economics of Codification and the Diffusion of Knowledge. Industrial and Corporate Change 6(3), 595-622 (1997)

3. Mokyr, J.: The Gifts of Athena: Historical Origins of the Knowledge Economy. Princeton University Press, Princeton (2002)

4. Williamson, O.E.: Markets and Hierarchies. Free Press, New York (1975)

5. Jack, S.L.: Approaches to studying networks: Implications and outcomes. Journal of Business Venturing 25, 120-137 (2010)

6. Ricciardi, A.: Le reti di imprese. Vantaggi competitivi e pianificazione strategica. Franco Angeli, Milano (2003) 
7. Antonelli, V., et al.: Le coalizioni aziendali. Caratteri del fenomeno e forme relazionali, Giappichelli, Torino (2008)

8. Bastia, P.: Gli accordi tra imprese. Fondamenti economici e strumenti informativi. CLUEB, Bologna (1989)

9. Camarinha-Matos, L.M., Afsarmanesh, H.: Collaborative networks: a new scientific discipline. Journal of Intelligent Manufacturing 16, 439-452 (2005)

10. Lewis, D.J.: Partnership for profit: structuring and managing strategic alliances. The Free Press, New York (1990)

11. Donkels, R., Lambrecht, J.: Networks and small business growth: an explanatory model. Small Business Economics 7, 273-289 (1995)

12. Macpherson, A., Holt, R.: Knowledge, learning and small firm growth: A systematic review of the evidence. Research Policy 36, 172-192 (2007)

13. Parker, S.C.: The economics of formal business networks. Journal of Business Venturing 23, 627-640 (2008)

14. Camarinha-Matos, L.M.: Collaborative Networked Organizations: Status and trends in manufacturing. Annual Reviews in Control 33, 199-208 (2009)

15. Afsarmanesh, H., Camarinha-Matos, L.M., Msanjila, S.S.: On management of 2nd generation Virtual Organizations Breeding Enviornments. Annual Reviews in Control 22, 209 219 (2009)

16. Afsarmanesh, H., Galeano, N., Camainha-Matos, L.M.: Characterization of key components, features, and operating principles of the Virtual Breeding Environment. Deliverable 21.1. ECOLEAD (2004)

17. Camarinha-Matos, L.M., Afsarmanesh, H., Galeano, N., Molina, A.: Collaborative networked organizations - Concepts and practice in manufacturing enterprises. Computers \& Industrial Engineering 57, 46-60 (2009)

18. Romero, D., Molina, A.: VO breeding environments \& virtual organizations integral business process management framework. Information Systems Frontiers 11, 569-597 (2009)

19. Lunghi, P., Tonelli, F., Rinaldi, R., et al.: MIGEN: Modelli e Strumenti Innovativi per la Gestione dei Network di imprse, Edizioni Anteo, Perugia, Italy (2008)

20. Botarelli, M., Taticchi, P., Cagnazzo, L.: The Virtual Development Office Framework for Business Networks: a Case Study from the Umbrian Packaging District. In: PRO-VE 2008, Poznan (September 2008)

21. Porter, M.: Competitive Advantage: creating and sustaining superior Performance. Free Press, New York (1985)

22. Abell, D.F.: Defining the business: the starting point of strategic planning. Prentice Hall, Englewood Cliffs (1980)

23. Birger, W.: A resource based view of the firm. Strategic Management Journal 5(2), 171$180(1984)$

24. Daft, R.L.: Organization theory and design. West Pub. Co., St.Paul (1983) 